\title{
Kinetics of Carboxylmethylation of the Charge Isoforms of Myelin Basic Protein by Protein Methyltransferase II
}

\author{
Claudio A. Caamaño, *Julio M. Azcurra, *Otto Z. Sellinger, and Robert Zand \\ Biophysics Research Division and Department of Biological Chemistry, and *Mental Health Research Institute, \\ University of Michigan, Ann Arbor, Michigan, U.S.A.
}

\begin{abstract}
The charge isoforms $(\mathrm{Cl}-\mathrm{C} 5)$ of bovine myelin basic protein (MBP) were used as substrates for the rat brain enzyme protein carboxylmethyltransferase (PM II). The objective of these experiments was to ascertain whether the kinetic behavior of the MBP isoforms reflected differences in the structures of this molecular family. Initial velocity plots as a function of the MBP-isoform concentration showed significant differences $(p<0.05)$ among the assayed isoforms except for isoforms $\mathrm{C} 2$ and $\mathrm{C} 4$. Under the conditions of our experiment all the curves exhibited a consistent sigmoidicity. The kinetic data were best fitted by a model, previously described for the enzyme $D$ - $\beta$-hydroxybutyrate dehydrogenase, in which two independent sites must be randomly occupied before
\end{abstract}

any catalytic activity can occur. This mechanism is substantially different from that proposed by other investigators for similar PM II enzymes and other substrates. The differences in the rates of isoform carboxylmethylation are largely accounted for by the different apparent dissociation constants $K_{\mathrm{s}}$ and is explained on the basis of inherent structural differences among the charge isoforms. Key Words: Carboxylmethylation-Myelin basic protein-Charge isoforms- $\mathrm{Ki}$ netics-Structure. Caamaño C. A. et al. Kinetics of carboxylmethylation of the charge isoforms of myelin basic protein by protein methyltransferase II. J. Neurochem. 53, 1883-1888 (1989).
Myelin basic protein (MBP) is one of the major protein components of the CNS myelin membrane. Its purification and chemical characterization from CNS white matter and from myelin of several mammals has been the object of numerous reviews (Dunkley and Carnegie, 1974; Martenson, 1980; Braun, 1984; Campagnoni, 1988). The ability of MBP to undergo posttranslational modifications, such as phosphorylation (Miyamoto and Kakiuchi, 1974; Martenson et al., 1983; Chan et al., 1987), deamidation (Deibler et al., 1975; Chou et al., 1976), glycation (Hitz and Dain, 1988), and methylation (Paik and Kim, 1968; Jones and Carnegie, 1974; Johnson and Aswad, 1985; Chanderkar et al., 1986; Young and Waickus, 1988) is also well documented.

Two types of methylation of the MBP are possible, $\mathrm{N}$-methylation and $O$-methylation, catalyzed respectively by protein methyltransferase (PM) I and II (EC 2.1.1.23 and EC 2.1.1.77) (Paik and Kim, 1980). The PM II enzyme has been shown to react with proteins in which D-aspartate or L-isoaspartate has selectively replaced certain normal L-aspartyl and L-asparaginyl residues (Clarke, 1985; Aswad and Johnson, 1987). Also, other structural requirements have been proposed as determinants of a protein's capability to be carboxylmethylated, viz. its degree of folding, its conformation, and its amino acid sequence (Brunauer and Clarke, 1986; Clarke, 1988; Galletti et al., 1988). The structural requirement for the substrate to be methylated by the enzyme might provide an avenue for evaluating the effect of the posttranslational modifications of the MBP on the structure and folding of the protein. The question of structural organization and folding of MBP has been a topic of considerable controversy. The finding of a hydrophobic region in the molecule was viewed as support for the presence of a small amount of organized structure that was generated by the folding process (Randall and Zand, 1985). Additional evidence favoring a specific chain folding in MBP was reported by Alvord et al. (1986). The charge
Received January 17, 1989; revised manuscript received April 27, 1989; accepted May 17, 1989.

Address correspondence and reprint requests to Dr. R. Zand at Biophysics Research Division, University of Michigan, Ann Arbor, MI 48109-2099, U.S.A.
Abbreviations used: ANOVA, analysis of variance; MBP, myelin basic protein; PM, protein methyltransferase; SAM, $S$-adenosyl-Lmethionine; SDS-PAGE, sodium dodecyl sulfate-polyacrylamide gel electrophoresis. 
isoforms of MBP comprise differentially phosphorylated, arginine (107) methylated, and glutamine/asparagine deamidated species of the protein that may exhibit differences in structure and folding. Because each of the charge isoforms of bovine MBP can be isolated in sufficient quantity to permit its use in an extended study with the methylating enzymes, it was of interest to determine whether the isoforms exhibited differing propensities for carboxylmethylation.

The carboxylmethylation of MBP has been documented by several laboratories (Johnson and Aswad, 1985; Innami et al., 1986). Both the cytosolic and membrane-solubilized forms of cerebral PM II have been found to be active in this reaction (Sellinger et al., 1987, 1988). From a physiologic consideration, both MBP and PM II are found in high concentrations in brain, and in vitro studies noted above have demonstrated that MBP is one of the best substrates found to date for this enzyme. Although an in vivo demonstration of MBP methylation has not been reported, its occurrence could be masked by the extreme lability of the ester linkage and its low level of incorporation into MBP.

The present report provides evidence that: (a) all MBP charge isoforms are effective substrates for the cytosolic PM II enzyme, (b) the kinetics of carboxylmethylation show significant differences among the MBP isoforms assayed, and (c) the carboxylmethylation of MBP proceeds via a mechanism that differs substantially from that described for the carboxylmethylation of two previously examined proteins ( Jamaluddin et al., 1975; Billingsley et al., 1985).

\section{MATERIALS AND METHODS}

\section{Protein purification}

PM II. The cytosolic rat brain carboxylmethyltransferase that was used in this study was a gift from Dr. M. L. Billingsley, Department of Pharmacology, Pennsylvania State University, Hershey, PA, U.S.A. The purity of the enzyme was assessed as a single band on gel electrophoresis, as reported by Billingsley and Roth (1982). This preparation was free of endogenous methyl-accepting proteins.

$M B P$. The MBP was isolated from bovine brain and spinal cord white matter as follows. The delipidation procedure and subsequent MBP isolation from the delipidated tissue were based on the protocols of Chou et al. (1977), Lowden et al. (1966), and Liebes et al. (1975). The purification and isolation of the five major MBP charge isoforms was performed according to the procedure of Chou et al. (1976) but modified by us to enable the processing of a larger amount of protein. Typically, $600 \mathrm{mg}$ of MBP extract were dissolved in $25 \mathrm{ml}$ of a solution containing $6 \mathrm{M}$ urea (ultrapure grade, ICN Biochemicals, Cleveland, OH, U.S.A.) and $0.08 \mathrm{M}$ sodium glycinate, $\mathrm{pH}$ adjusted to 9.5 . This solution was centrifuged and then loaded $(3 \mathrm{ml} / \mathrm{min})$ onto a carboxymethyl cellulose (Whatman CM-52) column, $1.5 \times 30 \mathrm{~cm}$, previously equilibrated in a buffer of the same composition as the solution but adjusted to $\mathrm{pH} 10.5$. The column was washed with the equilibration buffer at a flow rate of $6 \mathrm{ml} / \mathrm{min}$ until no protein could be detected in the effluent. For elution of the MBP isoforms, a 0-180 $\mathrm{mM} \mathrm{NaCl}$ linear gradient in $2 M$ urea and $0.08 \mathrm{M}$ glycine, $\mathrm{pH} 10.5$, was used. The eluted charge isoforms were identified as fractions $\mathrm{C1}-\mathrm{C} 5$ according to their order of elution (Deibler and Martenson, 1972). The fractions corresponding to each component were pooled, rechromatographed, dialyzed against several changes of distilled water, lyophilized, and stored at $-20^{\circ} \mathrm{C}$. The purity of each component was checked by urea-sodium dodecyl sulfate-polyacrylamide gel electrophoresis (SDS-PAGE) and also by amino acid analysis.

\section{Assay of PM II activity}

The incubation mixture consisted of $1 \mu$ l of enzyme solution; $5 \mu \mathrm{l}(0.12 \mathrm{mCi})$ of $S$-adenosyl-L-[methyl $\left.-{ }^{3} \mathrm{H}\right]-$ methionine ( $\left.\left[{ }^{3} \mathrm{H}\right] \mathrm{SAM}\right)(68 \mathrm{Ci} / \mathrm{mmol}, \mathrm{ICN}$ Radiochemicals); $10 \mu \mathrm{l}$ of $200 \mathrm{~m} M$ sodium phosphate buffer, $\mathrm{pH} 6.4$; and variable amounts of MBP charge isoforms dissolved in distilled water $(6 \mathrm{mg} / \mathrm{ml})$, in a total volume of $90 \mu \mathrm{l}$. No nonradioactive SAM was added to this solution, and the $R S$ enantiomer composition of the radioactive material was not determined. The mixture was incubated at $37^{\circ} \mathrm{C}$ for $15 \mathrm{~min}$ (initial velocity conditions) and the reaction was terminated by the addition of $1 \mathrm{ml}$ of $10 \%$ trichloroacetic acid, followed by $0.1 \mathrm{ml}$ of bovine serum albumin $(1 \mathrm{mg} / \mathrm{ml})$ as carrier. The amount of methyl ester generated was determined by measuring the radioactivity of the $\left[{ }^{3} \mathrm{H}\right]$ methanol, liberated on mild alkaline hydrolysis and extracted according to the procedure given by Diliberto and Axelrod (1974).

In an analogous experiment with a different enzyme preparation and unfractionated MBP, at concentrations of 35 and $10 \mu \mathrm{M}$, respectively, $0.007 \mathrm{~mol}$ of methyl group per mole of protein were incorporated after I h of reaction. Under these conditions the maximum amount of methylation was obtained.

\section{Electrophoresis}

The assessment of MBP isoform purity utilized urea-SDSPAGE according to the protocol of Swank and Munkres (1971). The procedure was modified for our purposes and adapted for use with slabs $(140 \times 140 \times 0.7 \mathrm{~mm})$. Protein solutions (10-30 $\mu \mathrm{g}$ of protein), containing $0.5 \%$ SDS (wt/ $\mathrm{vol}), 10 \% \mathrm{glycerol}(\mathrm{vol} / \mathrm{vol}), 5 \% \beta$-mercaptoethanol (vol/vol), $8 M$ urea, and $0.01 M$ phosphoric acid, were adjusted to $\mathrm{pH}$ 6.8 with Tris base. The samples were then incubated at $65^{\circ} \mathrm{C}$ for $10 \mathrm{~min}$ prior to electrophoresis. The slab gel contained $0.1 \% \mathrm{SDS}$ (wt/vol), $8 \mathrm{M}$ urea, $8 \%$ acrylamide (wt/vol), $0.066 \%$ ammonium persulfate (wt/vol), and $0.066 \% N, N, N^{\prime}, N^{\prime}$-tetramethylenediamine $(\mathrm{vol} / \mathrm{vol})$. The ratio of bis-acrylamide to acrylamide was $1: 38$. Buffer reservoir solutions contained $0.1 \%$ SDS (wt/vol) plus $0.1 \mathrm{M}$ phosphoric acid adjusted to pH 6.8 with Tris base. Electrophoresis was carried out at room temperature with the direction of protein migration being toward the anode $(10 \mathrm{~mA}, 40 \mathrm{~V})$. Bands were visualized using the ultrasensitive silver stain method reported by Sammons et al. (1981).

\section{Protein concentrations}

The amount of protein was determined according to the method of Lowry et al. (1951). Bovine serum albumin was used as the standard. For the assay of PM II activity the concentration values corresponding to aliquots of the aqueous MBP isoforms dilutions were also corroborated by absorbance determinations at 276 (Liebes et al., 1975) and $220 \mathrm{~nm}$. Triplicate assays were performed in all the cases.

\section{HPLC of the carboxylmethylated proteins}

The HPLC was performed on an LKB system using a gel filtration TSK G3000 SW column $(8 \times 300 \mathrm{~mm})$. The column 
was equilibrated with $0.1 M \mathrm{Na}_{2} \mathrm{HPO}_{4} / 0.1 M \mathrm{KCl}, \mathrm{pH} 6.5$ buffer. Chromatography runs were carried out at room temperature and the eluting buffer was the same as the equilibrating buffer.

\section{Statistical methods}

The comparison of the rates of methylation of the MBP charge isoforms was carried out using a two-way analysis of variance test (ANOVA). The isoforms were compared in pairs, using triplicate values for each MBP concentration. The ANOVA assessment was a part of the commercial statistical computer program Statworks, version 1.2.

\section{RESULTS AND DISCUSSION}

The kinetics of the carboxylmethylation of the MBP isoforms was distinctive in that each isoform showed a consistent sigmoid curvature when the velocity of the reaction was plotted against the substrate concentration (Fig. 1). Although the concentration of the methyl donor was below its reported $K_{\mathrm{m}}$ value, the validity for initial velocity conditions was checked by the linearity of velocity versus time plots for the reaction. Analysis of variance of the kinetic data confirmed that significant differences $(p<0.05)$ in reaction rates existed among the pairs $\mathrm{Cl} / \mathrm{C} 3, \mathrm{Cl} / \mathrm{C} 4, \mathrm{Cl} / \mathrm{C} 2, \mathrm{C} 4 / \mathrm{C} 3$, and $\mathrm{C} 2 / \mathrm{C} 3$, whereas $\mathrm{C} 1$ was found to differ from $\mathrm{C} 5$ only at concentrations below $15 \mu M$. The isoforms $\mathrm{C} 2$ and $\mathrm{C} 4 \mathrm{did}$ not show any kinetic difference over the range of concentration that was studied. In the figures only the $\mathrm{C} 4$ curves are shown to illustrate the data. The observed differences in carboxylmethylation activity can result from differences in the geometry of the individual isoforms or they might arise from differences in the content of modified aspartyl residues present in each isoform. It is also possible that both of these factors contribute to the observed differences in kinetic behavior

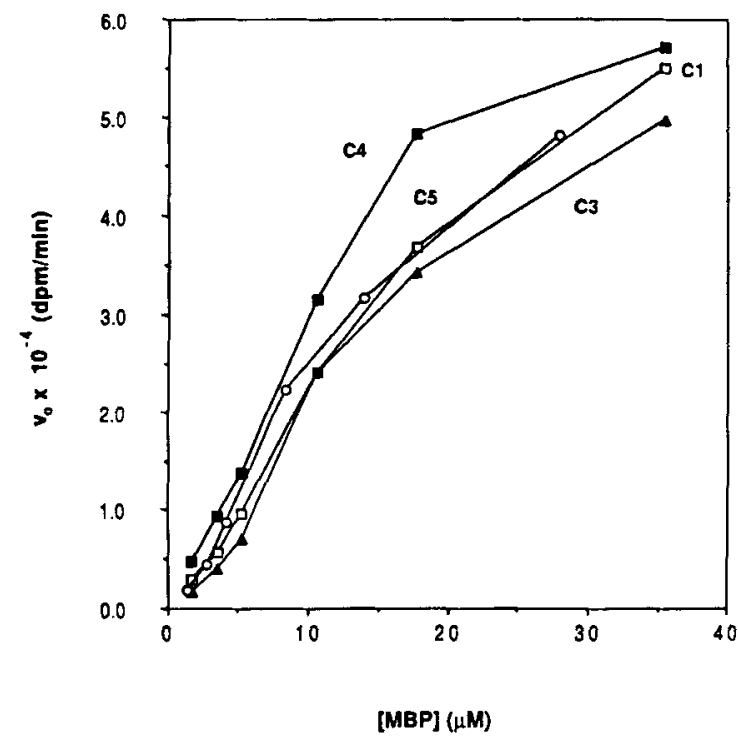

FIG. 1. Effect of the concentration of the different MBP-isoforms on the initial velocity of carboxylmethylation. The points represent the averages of triplicate assays. of the MBP isoforms. At the present time it is not possible to assess the contribution made by each of these factors. Different racemization levels of L-aspartate and L-serine have been reported by Shapira and Chou (1987) for the isoforms C1, C2, and C3. These investigators noted that the $\mathrm{C} 2$ isoform had the maximum content of $\mathrm{D}$-aspartate residues.

The possibility that the observed kinetic differences could be attributed to the presence of minor impurities or to molecular variants in the isolated isoforms was investigated using urea-SDS-PAGE, with silver staining and by HPLC analysis of the methylation products. The electrophoretic analysis of each of the five charge isoform proteins showed only a single band in each case, which represented more than $99 \%$ of the total applied protein. The elution pattern from the HPLC of the methylation reaction mixture using isoform $\mathrm{Cl}$ demonstrated the relationship between methylation, evaluated as methanol associated radioactivity, and the protein profiles. These data provide compelling support for the absence of any protein component with different PM Il substrate activity. Identical results were obtained for each of the other charge isoforms.

An earlier kinetic study by Jamaluddin et al. (1975), in which ribonuclease was used as the substrate and PM II was from calf thymus, was interpreted as indicating that the reaction involved a sequential rapid equilibrium yielding a random $\mathrm{Bi}-\mathrm{Bi}$ mechanism in which the rate-limiting step was the interconversion of the ternary complex of enzyme, SAM, and the protein substrate. According to this view, the kinetics should yield rectangular hyperbolic plots when constant amounts of enzyme are titrated as a function of substrate concentration. Such kinetics were not obtained in our system. Instead, sigmoidal curves were obtained which yielded curvilinear double-reciprocal plots (Fig. 2 ). We interpret this result as suggesting that either there is positive cooperativity for the binding of the protein substrate, or that the enzyme is required to bind a certain amount of substrate to convert to a catalytically active conformation. Hill plots for the reaction of the enzyme with the different charge isoforms were subjected to a least-squares computer analysis. The curves were biphasic with a slope approximating a value of 1.0 at high substrate concentrations (above $K_{\mathrm{m}}$ ) and 2.0 at low substrate concentrations (below $K_{\mathrm{m}}$ ). The failure to achieve a limiting slope of 1.0 at the lowest substrate concentrations compatible with measurements of enzyme kinetics can be viewed as supporting the requirement for the binding of two molecules of substrate protein to the PM II enzyme for the catalytic process to become operational.

The alternative possibility, namely the presence of positive cooperativity, was examined by treating the data according to the Hill equation:

$$
1 / v_{0}=1 / V_{\max }+K^{\prime} / V_{\max } \cdot 1 /[S]^{n}
$$

where $n$ is the number of substrate binding sites per molecule of enzyme, and $K^{\prime}$ is a constant comprising 


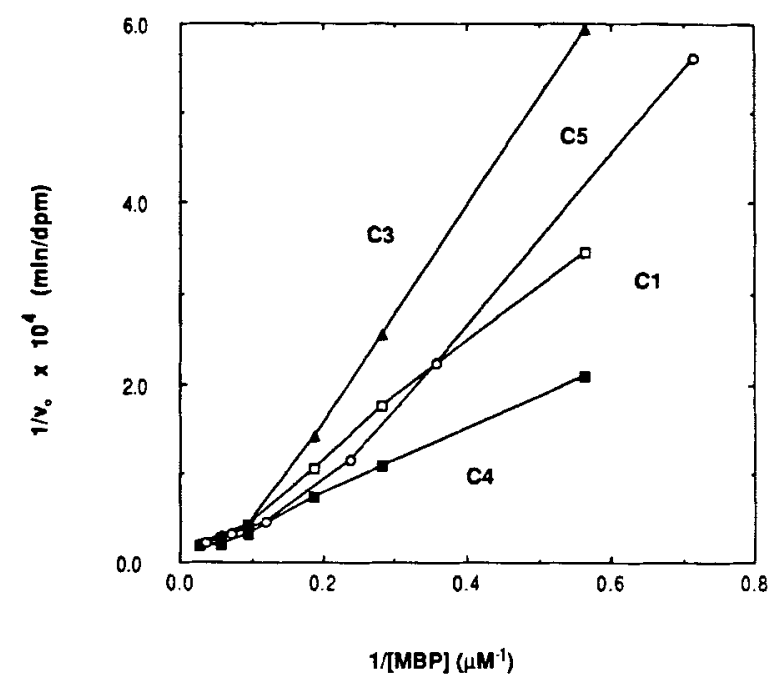

FiG. 2. Double-reciprocal Lineweaver-Burk representations for the MBP-isoforms.

$n-1$ interaction factors and $K_{5}$, the intrinsic equilibrium dissociation constant. If the enzyme possesses two strongly cooperative substrate sites, a linear plot should result when the data are plotted as $1 / v_{0}$ against $1 /[S]^{2}$. As seen in Fig. 3 this did not happen. Rather, the best fit to the experimental data was achieved using the following equation:

$$
\begin{aligned}
1 / v_{0}=1 / V_{\max }+2 K_{\mathrm{s}} / V_{\max } \cdot 1 /[S] & \\
& +K_{\mathrm{s}}{ }^{2} / V_{\max } \cdot 1 /[S]^{2}
\end{aligned}
$$

The kinetic analysis that results in the above equation was initially proposed by Cortese et al. (1982) to ac-

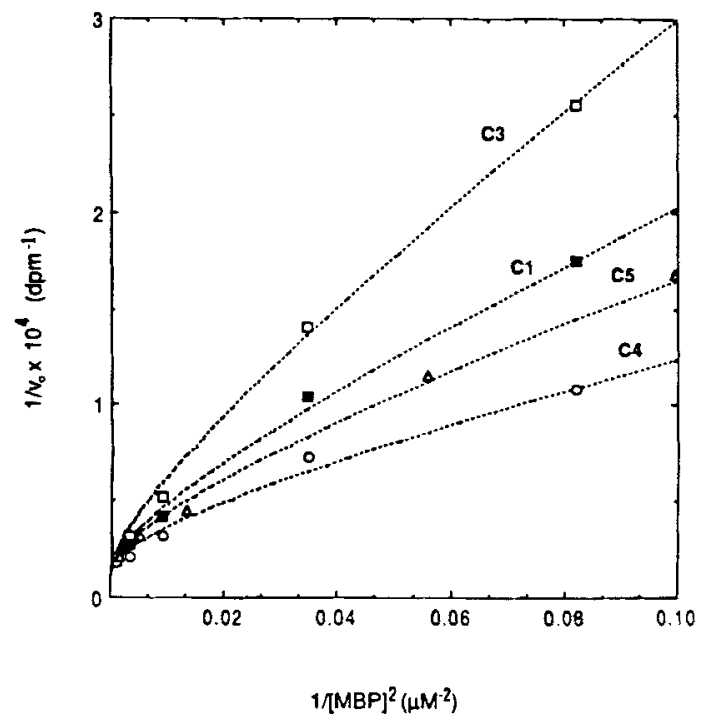

FIG. 3. Double-reciprocal plots of initial velocities as a function of the square of the MBP-isoform concentration. The experimental points are shown together with the representation (dotted lines) of the equation: $1 / V_{0}=1 / V_{\max }+2 K_{\mathrm{s}} / V_{\max } \cdot 1 /[S]+K_{\mathrm{s}}^{2} / V_{\max } \cdot 1 /[S]^{2}$. count for the kinetic behavior of the enzyme D- $\beta$-hydroxybutyrate dehydrogenase on activation by short fatty acid chain lecithins. This equation is valid for the presence of two noninteracting substrate sites and yields a linear plot when $1 / \sqrt{v_{0}}$ is plotted against $1 /$ [MBPisoform] (Fig. 4). Apparent values of $K_{\mathrm{s}}$ and $V_{\max }$ for all of the MBP isoforms used were obtained from the extrapolated intercept on the abscissa and from the intercept on the ordinate, respectively (Table 1 ). The kinetic parameters presented in this table should be regarded as strictly macroscopic in origin. Nevertheless, the probability of methylation at multiple sites with different kinetic constants is considered to be extremely limited because of the substoichiometric methylation that was obtained $(0.001 \mathrm{~mol}$ of methyl groups incorporated per mole of protein). The low level of methylation can be explained on the basis of the low enzymeto-substrate ratio utilized and the limited number of unique D-aspartate and L-iso-aspartate residues present which must, also, be located in favorable regions within the substrate sequence to be susceptible to reaction. It is not possible, at this time, to determine those sites that are amenable to methylation. In addition to the fit of the experimental data to Eq. 2 and the characteristic Hill plots that were obtained, an additional significant factor that appears to favor the two-site binding noncooperative interpretation over the cooperative counterpart is the coordinate for the inflection point in the plot of $v_{0}$ versus $[S]$. The coordinates obtained were $v_{0}=0.11 V_{\max }$ and $[S]=0.5 K_{\mathrm{s}}$. These values are identical to the values predicted for a system with two noninteracting essential sites (Segel, 1975).

The analysis of the data obtained in the present study permits several significant conclusions to be drawn. Although the differences in the kinetic parameters for the charge isoforms were never higher than twofold (Table 1), the data from which these parameters were

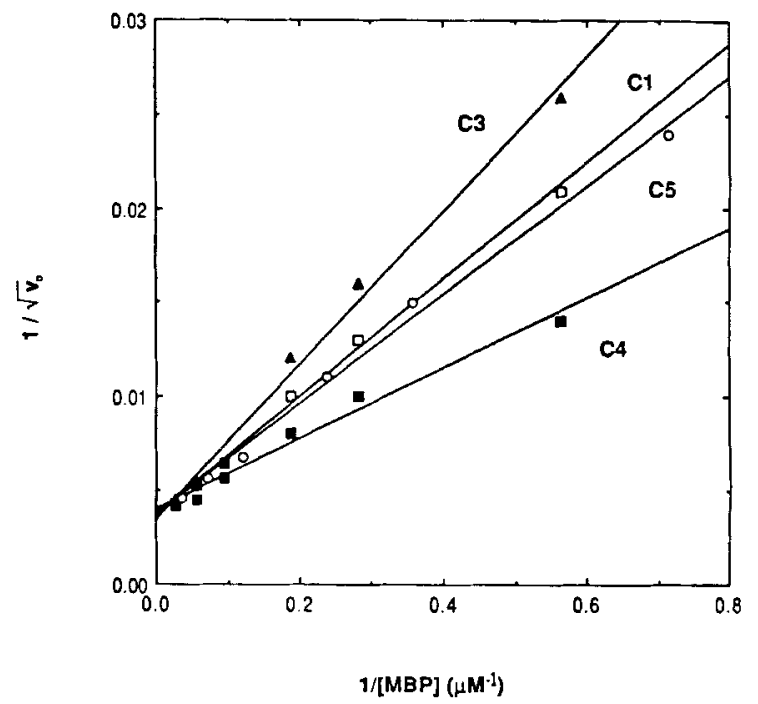

FIG. 4. Double-reciprocal plots of the square root of initial velocities as a function of the MBP-isoform concentration. 
TABLE 1. Kinetic parameters for the carboxylmethylation reaction

\begin{tabular}{lccccc}
\hline MBP isoform & $\mathrm{C} 1$ & $\mathrm{C} 2$ & $\mathrm{C} 3$ & $\mathrm{C} 4$ & $\mathrm{C} 5$ \\
\hline$V_{\max }{ }^{a} \times 10^{-3}(\mathrm{dpm} / \mathrm{min})$ & 79 & 76 & 81 & 76 & 77 \\
$K_{\mathrm{s}}^{a} \times 10^{6}(\mathrm{M})$ & 9.5 & 6.2 & 12.5 & 6.2 & 7.8 \\
Number of experiments & 6 & 5 & 4 & 4 & 4 \\
\hline
\end{tabular}

a The values of the constants were obtained from the $1 / \sqrt{v_{0}}$ versus 1/[MBP-isoform] plots shown in Fig. 4. In all the cases, the relative errors were lower than $8 \%$.

extrapolated (Fig. 1) showed significant differences among most of the isoforms. We believe that these differences support the assignment of specific geometric structures to the MBP isoforms. The subtle variations in geometry can be attributed to the posttranslational modifications of MBP which result in charge modifications of the parent protein. Although all the MBP isoforms tested in this study were active substrates, some were better than others, and we interpret this as being indicative of tertiary structural variations between isoforms. As noted above, alternative explanations for the kinetic behavior can be invoked. However, based upon recent circular dichroism studies that indicate differences in the $\beta$ structure content of the various charge isoforms, we consider this explanation to have the strongest support (Deibler et al., 1988; M. A. Moscarello, personal communication).

A second conclusion is that the reaction of PM II with MBP adheres to a kinetic format that is different from the kinetics that have been observed for the calf thymus enzyme with other protein substrates (Jamaluddin et al., 1975, 1976). It may be that similar kinetics would have been observed in these systems had the substrate concentrations been taken to lower values. Although deviations from Michaelis-Menten kinetics for the carboxylmethylation of several protein substrates have been noted by others at concentrations near $K_{\mathrm{s}}$ (Aswad and Deight, 1983; Billingsley et al., 1985), no kinetic explanation of these findings was suggested. Despite the observed deviations, various rearrangements of the Michaelis-Menten equations into linear forms were used to extrapolate $K_{\mathrm{s}}$ and $V_{\max }$ values (Aswad and Deight, 1983). Consequently such extrapolations may have yielded incorrect values for these kinetic parameters, especially when the substrate concentrations below $K_{\mathrm{s}}$ were specifically excluded in the treatment of the data. Nevertheless, our findings are the first observation of this kind of kinetic behavior for this enzyme.

Lastly, the mechanism of the reaction for PM II and MBP appears to be significantly different from that reported for this enzyme with other substrates (Jamaluddin et al., 1975). Additional studies will be needed to assess the generality of the present findings.

Acknowledgment: This research was supported in part by U.S. Public Health Service Grant NS 23474 to R.Z. and AG06071 to O.Z.S.

\section{REFERENCES}

Alvord E. C., Jr., Hruby S., Martenson R. E., Deibler G. E., and Law M. J. (1986) Evidence for specific polypeptide chain folding in myelin basic protein from reaction between fragments of the protein and monoclonal antibodies. $J$. Neurochem. 47, 764771.

Aswad D. W. and Deight E. A. (1983) Purification and characterization of two distinct isozymes of protein carboxymethylase from bovine brain. J. Neurochem. 40, 1719-1726.

Aswad D. W. and Johnson B. A. (1987) The unusual substrate specificity of eukaryotic protein carboxyl methyltransferases. Trends Biochem. Sci. 12, 155-158.

Billingsley M. L. and Roth R. H. (1982) Dopamine agonists stimulate protein carboxylmethylation in striatal synaptosomes. $J$. Pharmacol. Exp. Ther. 233, 681-688.

Billingsley M. L., Kincaid R. L., and Lovenberg W. (1985) Stoichiometric methylation of calcineurin by protein carboxyl $O$-methyltransferase and its effects on calmodulin stimulated phosphatase activity. Proc. Natl. Acad. Sci. USA 82, 5612-5616.

Braun P. (1984) Molecular organization of myelin, in Myelin (Morell P., ed), pp. 97-116. Plenum Press, New York.

Brunauer L. S. and Clarke S. (1986) Methylation of calmodulin at carboxylic residues in erythrocytes. Biochem. J. 236, 811-820.

Campagnoni A. T. (1988) Molecular biology of myelin proteins from central nervous system. $J$. Neurochem. 51, I-14.

Chan K. F. J., Moscarello M. A., Stoner G. L., and Webster H. deF. (1987) A novel fragmentation of human myelin basic protein: identification of phosphorylated domains. Biochem. Biophys. Res. Commun. 144, 1287-1295.

Chanderkar L. P., Paik W. K., and Kim S. (1986) Studies on myelin basic protein methylation during mouse brain development. Biochem. J. 240, 471-479.

Chou F. C.-H., Chou C.-H. J., Shapira R., and Kibler R. (1976) Basis of microheterogeneity of myelin basic protein. J. Biol. Chem. 251, 2671-2679.

Chou F. C.-H., Chou C.-H. J., Shapira R., and Kibler R. (1977) Modifications of myelin basic protein which occur during its isolation. J. Neurochem. 28, 1051-1059.

Clarke S. (1985) Protein carboxyl methyltransferases: two distinct classes of enzymes. Annu. Rev. Biochem. 54, 479-506.

Clarke S. (1988) Perspectives on the biological function and enzymology of protein carboxyl methylation reactions in eucaryotic and procaryotic cells, in Advances in Post Translational Modifications of Proteins and Aging (Zappia V., Galletti P., Porta R., and Wold, F., eds), pp. 213-228. Plenum Press, New York.

Cortese J. D., Vidal J. C., Churchill P., McIntyre J. O., and Fleischer S. (1982) Reactivation of $D-\beta$-hydroxybutyrate dehydrogenase with short chain lecithins: stoichiometry and kinetic mechanism. Biochemistry 21, 3899-3908.

Deibler G. E. and Martenson R. E. (1972) Large scale preparation of myelin basic protein from central nervous tissue of several mammalian species. Prep. Biochem. 2, 139-165.

Deibler G. E., Martenson R. E., Kramer A. J., and Kies M. W. (1975) The contribution of phosphorylation and loss of $\mathrm{COOH}$-terminal arginine in the microheterogeneity of myelin basic protein. $J$. Biol. Chem. 250, 7931-7938.

Deibler G. E., Stone A. L., and Kies M. W. (1988) Effect of phosphorylation on structure of myelin basic protein. Trans. Am. Soc. Neurochem. 19, 116.

Diliberto E. J. and Axelrod J. (1974) Characterization and substrate specificity of a protein carboxymethylase in the pituitary gland. Proc. Natl. Acad. Sci. USA 71, 1701-1704.

Dunkley P. R. and Carnegie P. R. (1974) Isolation of myelin basic protein, in Research Methods in Neurochemistry (Marks N. and Rodnight R., eds), pp. 219-245. Plenum Press, New York.

Galletti P., Ingrosso D., Pontoni G., Oliva A., and Zappia V. (1988) Mechanism of protein carboxyl methyl transfer reactions: structural requirements of methyl accepting substrates, in Advances in Post Translational Modifications of Proteins and Aging (Zappia V., Galletti P., Porta R., and Wold F., eds), pp. 229-245. Plenum Press, New York. 
Hitz J. B. and Dain J. A. (1988) Glycation of myelin basic protein. Biochem. Arch. 4, 159-168.

Innami T., Miyake M., and Kakimoto Y. (1986) In vitro carboxymethylation of myelin basic protein. Neurosci. Res. 4, 143-151.

Jamaluddin M., Kim S., and Paik W. K. (1975) Studies on the kinetic mechanism of $S$-adenosylmethionine:protein $O$-methyltransferase of calf thymus. Biochemistry 14, 694-698.

Jamaluddin M., Kim S., and Paik W. K. (1976) A comparison of kinetic parameters of polypeptide substrates for protein methylase II. Biochemistry 15, 3077-3081.

Johnson B. A. and Aswad D. W. (1985) Enzymatic protein carboxyl methylation at physiological $\mathrm{pH}$ : cyclic imide formation explains rapid methyl turnover. Biochemistry 24, 2581-2586.

Jones G. M. and Carnegie P. R. (1974) Methylation of myelin basic protein by enzymes from rat brain. $J$. Neurochem. 23, 12311237.

Liebes L. F., Zand R., and Phillips W. D. (1975) Solution behavior, circular dichroism and $220 \mathrm{MH}_{\mathrm{z}} \mathrm{PMR}$ studies of the bovine myelin basic protein. Biochim. Biophys. Acta 405, 27-39.

Lowden J. A., Moscarello M. A., and Morecki R. (1966) The isolation and characterization of an acid soluble protein from myelin. Can. J. Biochem. 44, 567-577.

Lowry O. H., Rosebrough N. J., Farr A. L., and Randall R. J. (1951) Protein measurement with the Folin phenol reagent. J. Biol. Chem. 193, 265-275.

Martenson R. E. (1980) Myelin basic protein: what does it do?, in Biochemistry of Brain (Kumar S., ed), pp. 49-79. Pergamon Press, New York.

Martenson R. E., Law M. J., and Deibler G. E. (1983) Identification of multiple in vivo phosphorylation sites in rabbit myelin basic protein. J. Biol. Chem. 258, 930-937.

McFadden P. N. and Clarke S. (1982) Methylation of D-aspartyl residues in erythrocytes: possible step in the repair of aged membrane proteins. Proc. Natl. Acad. Sci. USA 79, 2460-2464.

Miyamoto E. and Kakiuchi S. (1974) Phosphoprotein phosphatases for myelin basic protein in myelin and cytosol fractions of brain. Biochim. Biophys. Acta 384, 458-465.

Paik W. K. and Kim S. (1968) Protein methylase I: Purification and properties of the enzyme. J. Biol. Chem. 243, 2108-2114.

Paik W. K. and Kim S. (1980) Methylation of free carboxyl groups of proteins, in Protein Methylation (Meister A., ed), pp. 202231. John Wiley \& Sons, New York.

Randall C. S. and Zand R. (1985) Spectroscopic assessment of secondary and tertiary structure in myelin basic protein. Biochemistry 24, 1998-2004.

Sammons D. W., Adams L. D., and Nishizawa E. E. (1981) Ultra sensitive silver based color staining of polypeptides in polyacrylamide gels. Electrophoresis 2, 135-141.

Segel I. H. (1975) Enzyme Kinetics, pp. 401-403. John Wiley and Sons, New York.

Sellinger O. Z., Kramer C. M., Fischer-Bovenkerk C., and Adams C. (1987) The characterization of a membrane-bound protein carboxylmethylation system in brain. Neurochem. Int. 10, 155166.

Sellinger O. Z., Abdulkarem N., Duboff G. S., Webster T., and Wolfson M. F. (1988) The carboxylmethylation of myelin basic protein by the cerebral cytosolic and membrane-bound protein carboxylmethyltransferase, in Abstracts of the International Meeting on Neurochemical Aspects of Phospholipid Metabolism. p. 78. Perugia, Italy.

Shapira R. and Chou C.-H. J. (1987) Differential racemization of aspartate and serine in human myelin basic protein. Biochem. Biophys. Res. Commun. 146, 1342-1349.

Swank R. T. and Munkres K. D. (1971) Molecular weight analysis of oligopeptides by electrophoresis in polyacrylamide gel with sodium dodecyl sulfate. Anal. Biochem. 39, 462-477.

Young P. R. and Waickus C. M. (1988) Purification and kinetic mechanism of $S$-adenosylmethionine: myelin basic protein methyltransferase from bovine brain. Biochem. J. 250, 221-226. 